\title{
Attraction of Telenomus podisi to volatiles induced by Euschistus heros in three different plant species
}

\author{
Aline Moreira Dias ${ }^{1} \cdot$ Martín Pareja $^{2}$ (1) Maycon Laia $^{3}$. \\ Maria Carolina Blassioli-Moraes ${ }^{4} \cdot$ Miguel Borges $^{4} \cdot$ Raúl A. Laumann $^{4}$
}

Received: 6 November 2015/ Accepted: 14 July 2016/Published online: 29 July 2016

(C) Springer Science+Business Media Dordrecht 2016

\begin{abstract}
Specialized natural enemies that forage for polyphagous hosts need to locate hosts on different plants. Telenomus podisi (Hymenoptera: Platygastridae) is a stink bug egg parasitoid with a preference for Euschistus heros (Hemiptera, Pentatomidae), a polyphagous species. The aim of this study was to evaluate the induction of defences in three E. heros host plants: maize (Zea mays), sunflower (Helianthus annuus) and pigeon pea (Cajanus cajan). We hypothesized that $E$. heros damage to these three plants enhances the attraction of the parasitoid $T$. podisi as has been observed in other systems. Using Y-tube olfactometer bioassays, we tested parasitoid responses to combinations of the following odour sources: clean air, undamaged plants and plants damaged by stink bug feeding. Volatiles were collected by means of dynamic headspace collection and analysed by gas chromatography coupled to mass spectrometry. T. podisi did not distinguish odours from undamaged plants against air for any of the three plant species. For maize, the parasitoid preferred the odour from herbivore-damaged plants over both clean air and
\end{abstract}

Handling Editor: Jarmo Holopainen.

Martín Pareja

mpareja@unicamp.br

1 Programa de Pós-Graduação em Entomologia, Universidade Federal de Lavras - UFLA, Campus Universitário, Caixa Postal 3037, Lavras, MG 37200-000, Brazil

2 Departamento de Biologia Animal, Universidade Estadual de Campinas - UNICAMP, Rua Monteiro Lobato 255, Caixa Postal 6109, Campinas 13083-862, Brazil

3 Universidade de Brasília-UnB, Campus Darcy Ribeiro, Brasília 70910-900, Brazil

4 Embrapa Recursos Genéticos e Biotecnologia, Parque Estação Biológica - W5 Norte, Brasília 70770-917, Brazil undamaged plants. For sunflower, the parasitoid only preferred the odour of herbivore-damaged plants over the odour of undamaged plants. For pigeon pea, no preferences were observed. Quantitative differences in the volatile profile of damaged and undamaged plants were observed in each plant species. We conclude that sunflower and maize plants, when damaged by E. heros, release volatiles that attract the parasitoid $T$. podisi; the parasitoid appears to use a different blend composition to distinguish herbivoredamaged plants of each species.

Keywords Tritrophic interactions - Multitrophic interactions - Induced defence $\cdot$ Herbivore-induced plant volatiles

\section{Introduction}

Plants injured by herbivores release a specific blend of volatiles that attracts carnivorous insects, such as predators and parasitoids. These herbivore-induced plant volatiles (HIPVs) constitute part of the plant's indirect defence, since it increases natural enemy activity on the plant (de Boer et al. 2008; Dicke and Baldwin 2010; Hilker and Meiners 2010; Karban and Myers 1989; Pashalidou et al. 2010; van Poecke and Dicke 2004). HIPVs are emitted following metabolic changes in plants triggered by mechanical damage caused by the herbivore, as well as saliva that comes into contact with the damaged plant tissues (Hilker and Meiners 2010). Due to differences in feeding mode and saliva chemistry, these metabolic changes are highly specific, creating HIPVs signal that serves as a fingerprint for each type of damage (Koornneef and Pieterse 2008). Parasitoids that are specialized on a single species can often distinguish HIPVs induced by their hosts 
from those induced by non-host herbivores (De Moraes et al. 1998; Du et al. 1996). Response specificity is most often achieved by perception of specific ratios of different volatile compounds, or through whole-blend recognition (Bruce and Pickett 2011; McCormick et al. 2012; Pareja et al. 2009). Parasitoids that have a broader host range can show responses to HIPVs induced by different herbivores and often have plastic responses that are affected by the experience the adult has during its lifetime (Storeck et al. 2000; Vet and Dicke 1992).

Most of the studies on tritrophic interactions mediated by HIPVs have been carried out with simple systems, consisting of one species in each trophic level (Ode 2013). However, natural food webs are complex and constituted by multiple species at each level (Ode 2013; Rodríguez-Saona et al. 2005). Thus, plants are usually attacked by several herbivores, each of which can have many different natural enemies in any given community. Furthermore, these natural enemies have to forage for herbivores that use a complex of host plant species. Therefore, predators and parasitoids that attack polyphagous herbivores need to recognize the plants that are potential hosts of their prey/hosts. Since each plant species has an HIPV blend with some specificity, these natural enemies are faced with an enormously complex task when deciphering chemical information (Wäschke et al. 2013), especially due to the large intraspecific variability in volatile blends (Gouinguené et al. 2001). Some parasitoids are known to be able to recognize HIPVs from different plants that harbour their hosts. For example, the wasp Cardiochiles nigriceps Viereck, (Hymenoptera: Braconidae), a specialist parasitoid of polyphagous larvae of Heliothis virescens (Fabricius; Lepidoptera: Noctuidae), is attracted to HIPVs of plants from different families (Malvaceae, Solanaceae and Poaceae) induced by the attack of larvae of $H$. virescens but not to HIPVs induced by the closely related non-host Helicoverpa zea (Boddie) (De Moraes et al. 1998). However, we still know little about how parasitoids deal with the multiple potential plant species that a polyphagous herbivore may feed upon.

Telenomus podisi (Ashmead; Hymenoptera: Platygastridae) is an egg parasitoid of many stink bug species (Pentatomidae) (Laumann et al. 2009; Sujii et al. 2002) that recognizes HIPVs of plants induced by different stink bug species (Melo Machado et al. 2014; Michereff et al. 2011, 2013; Moraes et al. 2005, 2008), as well as the HIPVs released by two species of Fabaceae, Glycine max (L.) Merrill and Cajanus cajan (L.) Millspaugh, that suffer damage by its preferred host Euschistus heros (Fabricius; Hemiptera: Pentatomidae) (Moraes et al. 2005). In soybean, attraction of $T$. podisi depends on both plant genotype (Michereff et al. 2011; Moraes et al. 2005, 2008) and the species of stink bug causing the injury (Lopes et al. 2012). Several volatile compounds are released in higher quantities after E. heros damage to soybean (Michereff et al. 2011; Moraes et al. 2005, 2008). In addition, a population of this parasitoid that uses eggs of the rice stink bug, Tibraca limbativentris (Stal.) as hosts (Hemiptera: Pentatomidae), is selectively attracted to HIPVs induced by this herbivore in rice (Melo Machado et al. 2014).

Since the parasitoid $T$. podisi is attracted to volatiles of several species of legumes such as soybean and pigeon pea (Moraes et al. 2005) and E. heros has a polyphagous habit, we were interested in studying tritrophic interactions on other E. heros host plants. Thus, the aim of this study was to evaluate the induction of defences by E. heros in three crop species: sunflower, maize and pigeon pea. These plant species were used because they are known hosts of $E$. heros (Copatti and Oliveira 2011; Malaguido and Panizzi 1998; Panizzi and Vivan 1997). We hypothesized that $T$. podisi, being a generalist parasitoid, responds to the HIPV blend of different plant species damaged by E. heros. Furthermore, we expected that parasitoid responses to damaged plants are related to reliable volatile chemical signals that are conserved in different plant species. Understanding these interactions in multiple systems is essential for developing management strategies of natural enemies through association of different crops for enhancing biological control.

\section{Materials and methods}

\section{Insect and plant rearing}

Stink bugs and parasitoids were reared at $26 \pm 2{ }^{\circ} \mathrm{C}$, $60 \pm 10 \%$ relative humidity and 14 -h:10-h photoperiod in the Semiochemicals Laboratory, Embrapa Recursos Genéticos e Biotecnologia, Brasília, DF, Brazil. The stink bugs were reared using the procedure described by Borges et al. (2006). Adults were kept in 8-L plastic pots, with peanut [Arachis hypogaea (L.)], soybean and sunflower [Helianthus annus (L.)] seeds, fresh green beans [Phaseolus vulgaris (L.)] and water as natural diet. These cages were covered with cloth, which was fastened with a rubber band. Pieces of nylon screen were placed in the cages to serve as substrate for insect oviposition. To obtain eggs of known age, the egg masses were collected daily.

Couples of $T$. podisi were kept in $25 \mathrm{~cm}^{2}$ plastic tissue culture flasks (ICN Biomedicals, Irvine, CA) capped with a cotton swab. Honey was offered as food for adults. E. heros eggs $(<24 \mathrm{~h})$ were offered as a host and left for $48 \mathrm{~h}$ to allow parasitism to occur. After this period, the eggs were transferred into another flask to allow the parasitoid larvae to develop and emerge. Females that were used in the bioassays were mated, were fed, did not have oviposition experience and were $24-48 \mathrm{~h}$ into adulthood. 
The plants used were maize [Zea mays (L.)] var. BRS Caimbé (Poaceae; seeds provided by Embrapa Milho e Sorgo, Sete Lagoas, Minas Gerais, Brazil), Garden Sunflower Yellow Dwarf (H. annuus; Asteraceae; Isla Pro super seeds, reference number 392) and pigeon pea $(C$. cajan) var. BRS Mandarin (Fabaceae; BAS Category, Lote BSB 159/12, Safra 2011/2012, seeds provided by Embrapa Sementes Básicas). The seeds were planted in plastic pots $(10.5 \times 11 \mathrm{~cm}$, height $\times$ diameter $)$ with holes in the bottom, filled with sterile soil supplemented with NPK 10:10:10 and plant growth substrate (HA vegetable Tropstrato). The plants were kept in a greenhouse for germination and growth at $27{ }^{\circ} \mathrm{C}$, under natural lighting and a 14-h photoperiod. The plants were watered daily. For the olfactometer bioassays and volatile collection, we used sunflower plants and pigeon pea plants 25-30 days after germination, and maize plants 15-20 days after germination.

\section{Plant induction}

Induction of HIPVs was performed by feeding injury of stink bug adults (herbivory). Three virgin E. heros females were placed on each plant between 16:00 and 18:00 h. This procedure was adopted to relate volatile collection periods with bioassays (see below). To ensure no oviposition was carried out on the plant, females 8-10 days into adulthood were used, since the pre-reproductive period in this species is 10-12 days (Silva et al. 2008). The females were kept in direct contact with plants, during the whole period of plant induction, by covering plants with microporous plastic bags. Control plants were covered in the same way, but no insects were introduced.

\section{Bioassays}

To assess the response to plant volatiles, Y-tube olfactometer bioassays were performed. The olfactometer arena consisted of an acrylic plate $(19 \mathrm{~cm} \times 19 \mathrm{~cm})$ with a Y-shaped perforation (central body $8 \mathrm{~cm}, 7 \mathrm{~cm}$ arms separated by an angle of $80^{\circ}$ and $1.5 \mathrm{~cm}$ wide). This plate was fixed between two glass plates $(19 \mathrm{~cm} \times 19 \mathrm{~cm})$ : the top plate being transparent and the bottom plate translucent. The glass and acrylic plates were pressed together using large paper clips on either side (Moraes et al. 2005).

Inside the olfactometer, an air flow was created using aquarium pumps. Air was pumped into the system using silicone tubes at a flow rate of $0.7 \mathrm{~L} / \mathrm{min}$ (adjusted by means of flow meters) in a total of $0.35 \mathrm{~L} / \mathrm{min}$ for each arm of the "Y"-tube, filtered with activated charcoal, and humidified with distilled water. Air was carried into 3.2-L glass vessels with lids adapted for connecting silicone tubes for carrying air in and out of the vessels. These glass vessels contained the plants that served as odour sources in the experiments. After passing through the glass recipients, the air was carried into the arms of the olfactometer via silicone tubes. An air flow was established inside the olfactometer connecting an outflow at the base of the trunk connected to a vacuum pump adjusted at a flow rate of $0.2 \mathrm{~L} / \mathrm{min}$. Experiments were performed with the following combinations of odours: air against air (control and calibration of the system); undamaged plants $(U)$ against air; plants with herbivory damage $(H)$ against air; and plants with herbivory damage $(H)$ against undamaged plants $(\mathrm{U})$. Bioassays were carried out between 9:00 and 16:00 h on the third day after start of the injury. In this manner, bioassays were always performed in concordance with the time period of volatile collection (see below) and the time of day during which parasitoids are actively searching for hosts. Before the bioassays, female stink bugs were removed from the plants. Plants were carefully removed from their pots, and to avoid contamination with soil volatiles during the experiments, the soil was wrapped with aluminium foil.

A female parasitoid was placed in the release area of the olfactometer (base of the "Y"), and its behavioural response was assessed for $600 \mathrm{~s}$. The initial choice (which olfactometer arm the female first entered and remained for over $15 \mathrm{~s}$ ) and residence time in each arm were recorded. Each female was used only once and constituted a replicate. For each plant (maize, sunflower and pigeon pea), 12 plants or plant pairs were used for each experiment, and a total of 60 insect replicates were carried out for each bioassay. After every five replicates, the plants and the olfactometer were changed and the side of odour presentation odour sources was inverted.

\section{Volatile collection and analysis}

The volatile chemical profile of pigeon pea, sunflower and maize was characterized using dynamic headspace collection (Moraes et al. 2009). The headspace of all three species was collected individually from undamaged plants and from plants that suffered herbivore damage ( $n=11$ for each plant species and treatment). The volatiles of each species of plant were collected simultaneously under the same conditions of light and temperature as the bioassays. Volatiles were collected during $24 \mathrm{~h}$, starting $48 \mathrm{~h}$ after the start of damage. In this manner, volatile collection corresponded to the period of 48-72 after start the herbivory. This time period was chosen from previous reports showing that induction of HIPVs by stink bugs start after $48 \mathrm{~h}$ of herbivory injury (Michereff et al. 2011). The plant pots were wrapped with aluminium foil to avoid contamination with soil volatile during volatile collection and placed in 10-L glass chambers. 
The air, purified with an activated charcoal filter (20-40 mesh, Sigma-Aldrich, PA, USA), entered the system through a compressor pump at a flow rate of $1.0 \mathrm{~L} / \mathrm{min}$ through polytetrafluoroethylene (PTFE) tubes. Air was extracted through the top of the chamber using a vacuum pump at $0.6 \mathrm{~L} / \mathrm{min}$, thus creating a "push-pull" system with positive pressure within the chambers. This system avoids unwanted air inflow into the chambers, preventing contamination of samples. A glass tube containing $100 \mathrm{mg}$ of Porapak Q (50-80 mesh, Supelco, PA, USA) adsorbent was connected to the outflow of the chamber in order to retain the volatile compounds. The volatiles collected during each period were eluted with $1 \mathrm{~mL}$ of $n$-hexane and pre-concentrated to $100 \mu \mathrm{L}$ under $\mathrm{N}_{2}$ flow. The samples were stored at $-20^{\circ} \mathrm{C}$. For analysis, $1 \mu \mathrm{L}$ of $n$-tetracosane solution in $n$-hexane was added as an internal standard (IS), before concentration, at a final concentration in the sample of $5 \mu \mathrm{g} / \mathrm{mL}$.

For quantification, the samples were analysed by gas chromatography (GC; Agilent 7890, 60-m nonpolar DB-5 column, $0.32 \mathrm{~mm}$ diameter, $1.0-\mu \mathrm{m}$ film thickness, Supelco, Bellefonte, PA, USA), connected to a flame ionization detector (FID) at $270^{\circ} \mathrm{C}$ and using a temperature programme at $50^{\circ} \mathrm{C} / 1 \mathrm{~min}, 15^{\circ} \mathrm{C} / \mathrm{min}$ to $250^{\circ} \mathrm{C} / 20 \mathrm{~min}$. One microliter of each sample was injected in splitless mode with helium as carrier gas at a flow rate of $1.5 \mathrm{~mL} /$ $\min$.

For compound identification, selected extracts were analysed by gas chromatography-mass spectrometry GCMS (Agilent $5975 \mathrm{C}$ ) equipped with quadrupole analyser and a nonpolar DB-5 column $(30 \mathrm{~m}, 0.25 \mathrm{~mm}$ diameter, $0.25-\mu \mathrm{m}$ film thickness, Supelco, Bellefonte, PA, USA) with electron impact ionization $\left(70 \mathrm{eV}, 280^{\circ} \mathrm{C}\right)$. Samples were injected in splitless mode, and helium was used as carrier gas at a flow rate of $1 \mathrm{~mL} / \mathrm{min}$. The data were collected and analysed with the ChemStation software. The identification of compounds was obtained by comparison of the pattern of fragmentation of the sample with the compounds catalogued in spectral data libraries (NIST 2008) and by calculation of the retention index (RI). For compound confirmation, the fragmentation pattern and IR of the compounds were compared with those obtained from authentic standards, when these were available.

\section{Statistical analyses}

To analyse the initial choice of $T$. podisi, a logistic regression was fitted to estimate the probability of selection for each of the treatments. The hypothesis of no preference ( $50 \%$ probability of choice for each olfactometer arm) for a particular treatment was tested using a Wald $\chi^{2}$ statistic with one degree of freedom. The average residence time in each olfactometer area in each combination of treatments was calculated and submitted to the Wilcoxon test. For each plant species, the total amount of volatiles released 48-72 $\mathrm{h}$ after damage was compared between treatments using generalized linear models with gamma error distribution. To analyse the effect of herbivory on volatile composition of each plant species, MANOVA followed by principal component analyses (PCA) were performed. Before all volatile analyses, data were transformed as log (base 10). All analyses were performed using the R environment (R Development Core Team 2007).

\section{Chemicals}

Porapak Q (80-100 mesh) was purchased from Supelco (PA, USA). Hexane for HPLC ( $\geq 97 \%$ and redistilled), $\alpha$-pinene (98\%), $\alpha$-camphene (90\%), benzothiazole (96\%), $\beta$ pinene $(99 \%)$, myrcene $(90 \%)$, (Z)-3-hexenyl acetate (98\%), $\gamma$-terpinene (97\%), (E)-ocimene (90\%), benzaldehyde (99\%), indole (98.5\%), methyl salicylate (99\%) and $\alpha$-copaene (90\%) were purchased from Sigma-Aldrich (Steinheim, Germany). Linalool (98\%), (E)- $\beta$-caryophyllene $(80 \%)$ and limonene $(97 \%)$ were purchased from TCIAmerica (Portland, USA). Geranylacetone (mixture of isomers; $96 \%$ ) was purchased from TCI (Tokyo, Japan). (E)4,8-Dimethylnona-1,3,7-triene (DMNT) and $(E, E)-4,8,12$ trimethyltrideca-1,3,7,11-tetraene (TMTT) were provided by Dr. Michael A. Birkett from Rothamsted Research, England.

\section{Results}

\section{T. podisi olfactory response}

When clean air was presented through both arms, T. podisi responded equally to both odours (first choice- $-\chi_{1}^{2}=0.066$, $P=0.796)$. When pigeon pea plant odours were presented, T. podisi did not prefer undamaged plants $\left(\chi_{1}^{2}=1.318\right.$, $P=0.250)$ or herbivore-damaged plants $\left(\chi_{1}^{2}=0.515\right.$, $P=0.422$ ) over clean air. There was no difference in parasitoid response to odours from herbivore-damaged plants when tested against undamaged plants $\left(\chi_{1}^{2}=0.147\right.$, $P=0.701$; Fig. 1).

When sunflower odours were presented, T. podisi did not show a response to undamaged plants against clean air $\left(\chi_{1}^{2}=2.292, P=0.130\right)$, nor to plants with herbivory damage against clean air $\left(\chi_{1}^{2}=2.363, P=0.123\right) . T$. podisi preferred odours of sunflower plants with herbivory damage when contrasted with undamaged plants $\left(\chi_{1}^{2}=7.599, P=0.005\right.$; Fig. 1$)$.

$T$. podisi showed no response to odours from undamaged maize plants when presented against clean air $\left(\chi_{1}^{2}=1.829, P=0.176\right)$ but was selectively attracted to 
Fig. 1 First choice of the parasitoid Telenomus podisi in Y-tube olfactometer bioassays to pigeon pea, sunflower and maize odours: Analyses of the first choices were carried out with logistic regression, and statistical testing was performed by Wald $\chi^{2}$ to assess significance. *Represents values that were statistically significant $0.05>P>0.01$ and $* * 0.01>P>0.001$. The horizontal bars indicate the mean response ratio calculated from the logistic regression and the lines are the $95 \%$ CI. For each plant (maize, sunflower and pigeon pea), 60 replicates were carried out for each combination above. The numbers in parentheses represent the number of insects which do not respond to any odours offered
Air

Undamaged plants

Plants damaged by $E$. heros

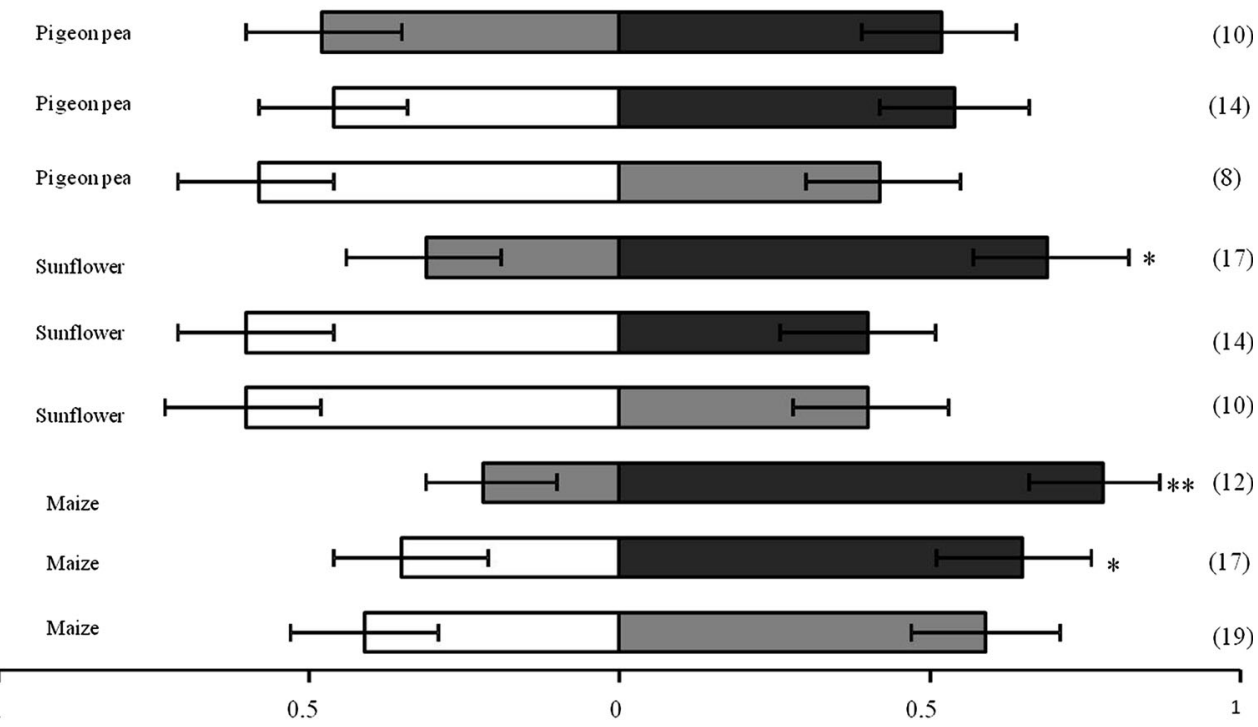

First choice (proportion of individuals) plants that suffered herbivory damage over clean air $\left(\chi_{1}^{2}=6.676, \quad P=0.009\right)$ and over undamaged plants $\left(\chi_{1}^{2}=15.280, P<0.001 ;\right.$ Fig. 1$)$.

\section{Volatile analyses}

The volatile blend showed qualitative differences between plant species but did not show differences between undamaged and damaged plants of the same species (Table 1.) Seventeen compounds were identified from pigeon pea plants, and the qualitative composition was similar in both damaged and undamaged plants (Table 1). Undamaged plants released larger quantities of volatiles than herbivoredamaged plants $\left(t_{20}=-2.143, P=0.044\right.$; Fig. 2). Individual tests for each compound were not carried out because of the multivariate nature of the data. MANOVA showed no significant effect of treatments on volatile composition (Pillai test $F_{4,170}=0.948, P=0.590$ ). The first two components of the PCA explained $78.28 \%$ of the total variability, but the PCA did not separate the blends of damaged and undamaged plants (Fig. 3).

Twenty compounds were identified in sunflower plants of both treatments (Table 1). The total quantities of volatiles released after 48-72 h of E. heros female damage was larger than that released by undamaged plants $\left(t_{20}=2.765\right.$, $P=0.011$; Fig. 2). MANOVA showed a marginal nonsignificant effect (Pillai test $F_{1,190}=77.930, P=0.061$ ), the first two components of the PCA explaining $78.63 \%$ of the total variability, and plants injured by stink bugs were clearly discriminated from undamaged plants (Fig. 3). The most important compounds that explained this PCA separation were sabinene, geranylacetone, $\gamma$-terpinene and $\alpha$ pinene (associated with damaged plants) and 2-ethyl hexanol (associated with undamaged plants).

From maize, 19 compounds were identified. The total amount of volatiles released after $48 \mathrm{~h}$ to $72 \mathrm{~h}$ was different between the treatments $\left(t_{20}=2.095, P=0.049\right)$, and undamaged plants released a larger quantity of compounds (Fig. 2). MANOVA showed a significant effect of treatments (Pillai test $F_{2,190}=274.600, P=0.036$ ), and the PCA separated the blends from damaged and undamaged. The first two components of PCA explained 78.32\% of the total variability (Fig. 3). The most important compounds that explained separation of plant by treatment were TMTT, cyclohexyl isothiocyanate, linalool, geranylacetone, benzothiazole and $\delta$-cadinene, all associated with undamaged plants.

\section{Discussion}

The parasitoid $T$. podisi showed a preference for volatiles emitted by sunflower, when contrasted with undamaged plants, and maize plants that had suffered feeding damage by $E$. heros, but was not attracted to pigeon pea plant volatiles. Thus, our results indicate that induced responses in sunflower and maize after $48-72 \mathrm{~h}$ of damage can signal herbivore presence on these plant species. Previously, 
Table 1 Volatile compounds (ng/plant/24 h of collection) from pigeon pea, sunflower and maize (mean \pm standard error) undamaged plants and plants injured by herbivory of Euschistus heros. Volatiles were collected after $48-72 \mathrm{~h}$ of herbivory in a period of $24 \mathrm{~h}$ of air entrainment. The retention index was calculated using a DB5 column

\begin{tabular}{|c|c|c|c|c|c|c|c|}
\hline \multirow[t]{2}{*}{ Compounds } & \multirow{2}{*}{$\begin{array}{l}\text { Retention } \\
\text { index }\end{array}$} & \multicolumn{2}{|l|}{ Pigeon pea } & \multicolumn{2}{|l|}{ Sunflower } & \multicolumn{2}{|l|}{ Maize } \\
\hline & & UD & Herbivory & UD & Herbivory & UD & Herbivory \\
\hline$\alpha$-Thujene $^{\mathrm{a}}$ & 930 & - & - & $0.002 \pm 0.006$ & $0.067 \pm 0.089$ & - & - \\
\hline$\alpha$-Pinene & 939 & $0.252 \pm 0.250$ & $0.227 \pm 0.350$ & $4.752 \pm 5.885$ & $18.189 \pm 24.756$ & - & - \\
\hline Camphene & 955 & - & - & $0.584 \pm 0.634$ & $0.812 \pm 1.059$ & - & - \\
\hline Sabinene & 977 & - & - & $2.459 \pm 1.521$ & $7.795 \pm 6.871$ & - & - \\
\hline$\beta$-Pinene & 981 & $0.987 \pm 1.932$ & $0.090 \pm 0.147$ & $0.824 \pm 0.978$ & $1.251 \pm 1.291$ & - & - \\
\hline $\begin{array}{l}\text { 6-Methyl-5-heptene- } \\
\text { 2-one }\end{array}$ & 984 & $0.494 \pm 0.633$ & $0.221 \pm 0.348$ & $0.196 \pm 0.098$ & $0.270 \pm 0.191$ & $0.036 \pm 0.019$ & $0.031 \pm 0.040$ \\
\hline$\beta$-Myrcene & 990 & $0.076 \pm 0.192$ & $0.045 \pm 0.076$ & $0.035 \pm 0.055$ & $0.109 \pm 0.142$ & $0.008 \pm 0.011$ & $0.025 \pm 0.052$ \\
\hline $3-$ Octanol $^{\mathrm{a}}$ & 995 & $0.054 \pm 0.119$ & $0.019 \pm 0.043$ & - & - & - & - \\
\hline $\begin{array}{l}\text { Cyclohexyl } \\
\text { isocyanate }\end{array}$ & 1000 & - & - & $0.062 \pm 0.053$ & $0.076 \pm 0.041$ & - & - \\
\hline $\begin{array}{l}\text { (Z)-3-Hexenyl } \\
\text { acetate }\end{array}$ & 1005 & $0.245 \pm 0.615$ & $0.240 \pm 0.502$ & - & - & - & - \\
\hline 2-Ethyl-1-hexanol ${ }^{\mathrm{a}}$ & 1032 & $0.615 \pm 0.691$ & $0.257 \pm 0.369$ & $1.566 \pm 1.633$ & $0.994 \pm 1.210$ & - & - \\
\hline Limonene & 1033 & $0.042 \pm 0.066$ & $0.141 \pm 0.155$ & $0.508 \pm 0.541$ & $1.165 \pm 0.664$ & $0.057 \pm 0.039$ & $0.046 \pm 0.049$ \\
\hline (E)- $\beta$-Ocimene & 1049 & $0.123 \pm 0.183$ & $0.072 \pm 0.095$ & $0.672 \pm 0.377$ & $0.457 \pm 0.281$ & $0.006 \pm 0.009$ & $0.003 \pm 0.009$ \\
\hline (E)-2-Octenal & 1058 & - & - & - & - & $0.033 \pm 0.031$ & $0.091 \pm 0.123$ \\
\hline$\gamma$-Terpinene & 1062 & $0.481 \pm 1.114$ & $0.315 \pm 0.559$ & $0.185 \pm 0.148$ & $0.589 \pm 0.848$ & - & - \\
\hline Linalool & 1100 & $0.788 \pm 0.811$ & $0.607 \pm 0.658$ & - & - & $0.109 \pm 0.073$ & $0.091 \pm 0.210$ \\
\hline DMNT & 1114 & $3.296 \pm 5.400$ & $0.198 \pm 0.287$ & $0.754 \pm 0.613$ & $0.684 \pm 0.399$ & $0.016 \pm 0.014$ & $0.008 \pm 0.016$ \\
\hline 4-Ethylbenzaldehyde & 1170 & $0.101 \pm 0.105$ & $0.108 \pm 0.134$ & - & - & - & - \\
\hline Methyl salicylate & 1199 & $0.161 \pm 0.388$ & $4 \times 10^{-4} \pm 0.001$ & - & - & $0.006 \pm 0.011$ & $0.001 \pm 0.004$ \\
\hline Benzothiazole & 1227 & $0.085 \pm 0.102$ & $0.103 \pm 0.130$ & $0.050 \pm 0.055$ & $0.282 \pm 0.436$ & $0.047 \pm 0.090$ & $0.007 \pm 0.016$ \\
\hline $\begin{array}{l}\text { Cyclohexyl } \\
\text { isothiocyanate }^{\mathrm{a}}\end{array}$ & 1236 & - & - & $0.619 \pm 0.651$ & $0.650 \pm 0.857$ & $0.213 \pm 0.190$ & $0.087 \pm 0.071$ \\
\hline Indole & 1290 & - & - & - & - & $0.049 \pm 0.035$ & $0.015 \pm 0.071$ \\
\hline$(+)$-Cyclosativene & 1370 & - & - & - & - & $0.425 \pm 0.699$ & $0.149 \pm 0.203$ \\
\hline$\beta$-Cubebene ${ }^{\mathrm{a}}$ & 1422 & - & - & - & - & $0.085 \pm 0.117$ & $0.060 \pm 0.069$ \\
\hline Sesquiterpene NI & 1433 & - & - & - & - & $0.026 \pm 0.049$ & $0.008 \pm 0.016$ \\
\hline$\alpha$-Copaene & 1372 & - & - & $0.122 \pm 0.103$ & $0.201 \pm 0.118$ & - & - \\
\hline$\beta$-Caryophyllene & 1423 & - & - & $0.196 \pm 0.094$ & $0.167 \pm 0.102$ & - & - \\
\hline$\beta$-Gurjunene ${ }^{\mathrm{a}}$ & 1435 & - & - & $0.043 \pm 0.051$ & $0.311 \pm 0.311$ & - & - \\
\hline Geranylacetone & 1448 & $1.266 \pm 1.175$ & $1.094 \pm 1.272$ & $0.456 \pm 0.216$ & $0.717 \pm 0.412$ & $0.150 \pm 0.095$ & $0.049 \pm 0.050$ \\
\hline$\alpha$-Muurolene ${ }^{\mathrm{a}}$ & 1482 & - & - & - & - & $0.033 \pm 0.061$ & $0.044 \pm 0.046$ \\
\hline$\delta$-Cadinene ${ }^{\mathrm{a}}$ & 1512 & - & - & - & - & $0.053 \pm 0.083$ & $0.011 \pm 0.014$ \\
\hline$\beta$-Cadinene ${ }^{\mathrm{a}}$ & 1520 & - & - & - & - & $0.078 \pm 0.092$ & $0.039 \pm 0.031$ \\
\hline TMTT & 1571 & $0.926 \pm 1.109$ & $0.769 \pm 0.914$ & $0.910 \pm 0.361$ & $1.174 \pm 0.419$ & $0.379 \pm 0.385$ & $0.057 \pm 0.060$ \\
\hline
\end{tabular}

UD—undamaged plants; DMNT—-(E)-4,8-dimethylnona-1,3,7-triene; TMTT—(E,E)-4,8,12-trimethyltrideca-1,3,7,11-tetraene

${ }^{a}$ Compounds tentatively identified by comparisons of spectra and retention indices, as no authentic samples were available

Moraes et al. (2005, 2008) and Michereff et al. (2011) observed that the parasitoid T. podisi was attracted to volatiles from soybean plants damaged by $E$. heros. The same behaviour was observed for this parasitoid when presented with rice HIPVs induced by T. limbativentris (Melo Machado et al. 2014). The use of these HIPVs, as well as other cues, such as host sex pheromones (Borges et al. 1999) or defensive compounds (Laumann et al. 2009), 

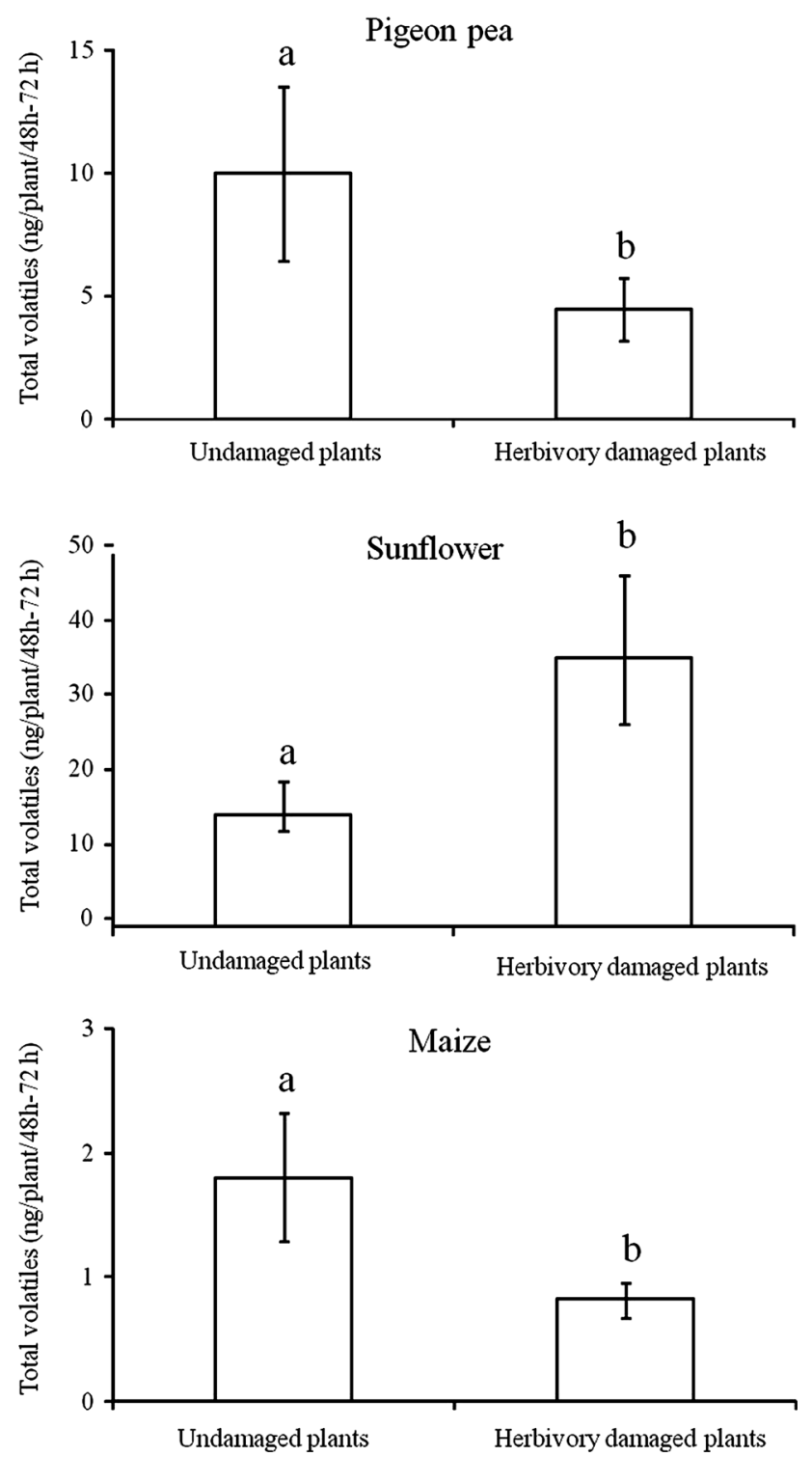

Fig. 2 Total volatiles $($ mean $+\mathrm{SE}$ ) released by plants of pigeon pea, sunflower and maize undamaged and damaged by herbivory of the stinkbug Euschistus heros. Volatiles were collected after 48-72 h of injury by herbivory of the stink bug. Different letters above each column indicate significant differences between treatments in each plant species (GLM analyses with gamma distribution of errors, $P<0.05)$

is likely due to the higher detectability of these volatiles compared to direct cues from the egg masses (Colazza et al. 2004a, b; Fatouros et al. 2008; Laumann et al. 2011). This increases the likelihood of finding their inconspicuous, aggregated (Higuchi 1992; Tillman et al. 2009) hosts in complex environments (Laumann et al. 2011). Besides the attraction of the parasitoid to blends of HIPVs from different plant species, the response is not a general response to any HIPV blend, but appears to involve a high degree of specificity and blend recognition. This corresponds with previous reports that suggest that $T$. podisi responses appear to be highly selective. For example, $T$. podisi females are able to recognize and discriminate HIPVs of rice elicited by injury of females of the rice stink bug T. limbativentis but not HIPVs induced by males (Melo Machado et al. 2014), and the production of HIPVs by soybean plants was higher when damaged by feeding $E$. heros females compared to males and nymphs (Moraes et al. 2005).

Volatile blends showed qualitative differences between plant species but did not show differences between undamaged and damaged plants of the same species. However, as was observed in soybean when injured by $E$. heros herbivory (Michereff et al. 2011; Moraes et al. 2005), quantitative differences were found in the three plant species evaluated, though no clear separation between blends was observed in the PCA for pigeon pea plants in this study. Moraes et al. (2005) showed that this plant species could be induced by E. heros damage, resulting in a specific blend of volatiles that attracted females of $T$. podisi. This difference is interesting and could be related to possible genetic variation in the pigeon pea used in each study, since different cultivars vary in HIPV production (Fritzsche Hoballah et al. 2002; Michereff et al. 2011) or, alternatively, due to different induction time courses in different species. For maize and sunflower, the PCAs suggest that a specific blend, including compounds found in very small quantities, could be relevant for stimulating the searching behaviour of the parasitoid. In pigeon pea, methyl salicylate and DMNT decreased in damaged plants, and these compounds are known to play a role in parasitoid attraction (Michereff et al. 2011; Rodriguez-Saona et al. 2011), so this could, in principle, be related to the lack of attraction to herbivore-damaged pigeon pea plants. In sunflower, damaged plants released a greater total amount of volatiles, driven primarily by an increase in the release of several terpenoids. In maize and pigeon pea, plants released lower amounts of volatiles and several terpenoids decreased emission rates; the same results were found by Kariyat et al. (2012), where damaged inbred horsenettle plants (Solanum carolinense L.) exhibited weaker volatile induction.

The overall comparison of blends shows some similarities, but several important differences in the blends of the three species. The compounds 6-methyl-5-hepten-2-one, $\beta$ myrcene, limonene, $(E)$ - $\beta$-ocimene, DMNT, benzothiazole, geranylacetone and TMTT were shared by the three species. More interestingly, no commonalities could be observed relating to attraction of $T$. podisi. In sunflower, where damage enhanced $T$. podisi attraction, terpenoid emission increased with damage, and some compounds ( $\alpha$ pinene and geranylacetone) have been previously found in attractive blends in soybean. In maize, on the other hand, damage decreased terpenoid emission, but increased 


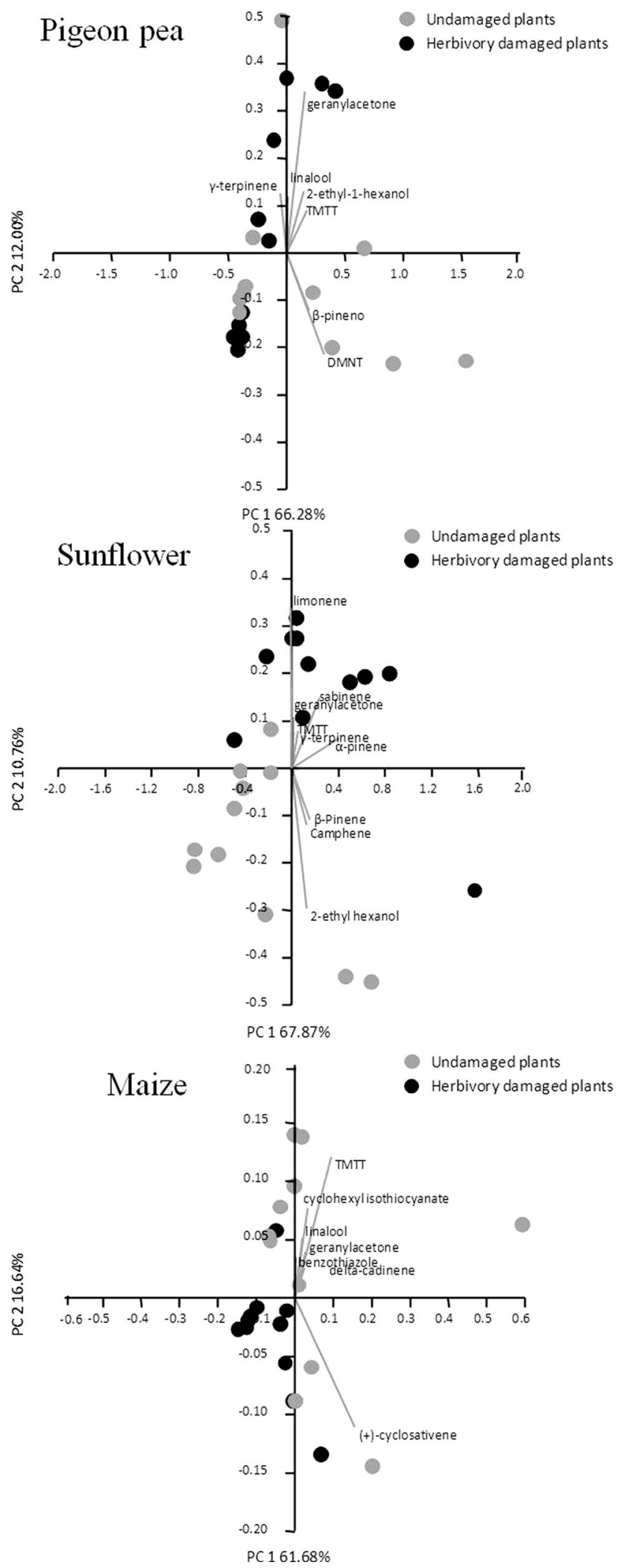

4Fig. 3 Principal component analyses (PCA) indicating differences in the composition of the volatile of sunflower pigeon pea and maize plants undamaged and after 48-72 h of injury by Euschistus heros. The circles represent the individual scores for each individual (plant) considering the two first components (PC1 and PC2). The lines represent the compounds with higher loads in the PCA and with higher contribution for the differentiation of treatments

parasitoid attraction. As is well known, maize plants from different genotypes can release different volatile blends (Gouinguené et al. 2001), and parasitoids may respond with more flexibility to the odours released from maize plants. This reveals that the qualitative identity of attractive blends could be highly variable between species. Methyl salicylate and (Z)-3-hexenyl acetate have been associated with soybean blends attractive to T. podisi (Michereff et al. 2011; Moraes et al. 2008, 2009) and were found in pigeon pea (both compounds) and maize plants (only methyl salicylate), but no direct relation was observed with parasitoid attraction. This can be related to the fact that the mere presence of these compounds does not elicit $T$. podisi attraction, which is the result of the interaction of the compounds with the plant volatile blend (Michereff et al. 2013). Whether these compounds are playing a part in plant signalling, through relative contribution to the blend, requires further behavioural and electrophysiological study. However, it highlights how blends appear to acquire their own identity, and individual compounds could have different effects depending on the background upon which they are presented (Bruce and Pickett 2011; McCormick et al. 2012; Michereff et al. 2013). The relevance of background odours in the behaviour of parasitoids is receiving increased attention (D'Alessandro et al. 2009; Hilker et al. 2002; Mumm and Hilker 2005; Mumm et al. 2003; Pareja et al. 2009), and this context dependence of individual compounds could prove to be widespread. This could be relevant for explaining the results observed for sunflower, where the parasitoid responds to damaged plants when compared to undamaged plants, but not when compared to air. It is possible that a contrast of odours is necessary for effective discrimination due to the background upon which it is presented (Hilker and McNeil 2008; Piñero and Dorn 2007).

The results presented here show that these parasitoids can selectively forage on a range of plants, as was previously demonstrated for parasitoids of chewing insects (De Moraes et al. 1998). Despite very different blends, T. podisi can identify host presence on different plant species. This is likely to enable the parasitoid to exploit its host 
independently of fluctuations in herbivore host use. Similarly to other stink bug species, E. heros feeds preferentially on legumes (Panizzi 1997) so an interesting perspective for future work is to test whether this parasitoid prefers legumes over other host plants. T. podisi is known to be selective in its response to soybean HIPVs (Lopes et al. 2012), defensive stink bug compounds (Laumann et al. 2009) and substrate borne vibratory signals (Laumann et al. 2011). If there are preference hierarchies between species in nature, some plant species might constitute relative enemy-free space for the herbivore, which may influence the maintenance of herbivore polyphagy.

We have shown that the parasitoid T. podisi can distinguish and respond to HIPVs in two plant species that are food plants for its host E. heros. Elucidating the mechanisms by which the parasitoid accomplishes this, despite very different blend compositions, promises to give insights into insect cognitive ecology and integration of complex signals. Further pest management research should aim at understanding whether these behavioural responses can serve as management tactics for maintaining parasitoid presence on a landscape scale, through provision of alternative food plants for its host.

Acknowledgments This work received financial support from the Conselho Nacional de Desenvolvimento Científico e Tecnológico$\mathrm{CNPq}$, through a studentship to AMD, as well as grants from Embrapa, CNPq and FAP-DF. MP was supported by a FAEPEXPAPDIC grant from UNICAMP.

\section{References}

Borges M, Costa MLM, Sujii ER, Cavalcanti MG, Redígolo GF, Resck IS, Vilela EF (1999) Semiochemical and physical stimuli involved in host recognition by Telenomus podisi (Hymenoptera: Scelionidae) toward Euschistus heros (Heteroptera: Pentatomidae). Physiological Entomology 24:227-233

Borges M, Laumann RA, Silva CC, Moraes MCB, Santo SHM, Ribeiro DT (2006) Metodologias de criação e manejo de colônias de percevejos da soja (Hemiptera: Pentatomidae) para estudos de comportamento e ecologia química. Brasília: Embrapa - Cenargen. 18p. Documentos, n. 182

Bruce TJA, Pickett JA (2011) Perception of plant volatile blends by herbivorous insects-finding the right mix. Phytochemistry 72:1605-1611. doi:10.1016/j.phytochem.2011.04.011

Colazza S, Fucarino A, Peri E, Salerno G, Conti E, Bin F (2004a) Insect oviposition induces volatile emission in herbaceous plants that attracts egg parasitoids. J Exp Biol 207:47-53

Colazza S, McElfresh JS, Millar JG (2004b) Identification of volatile synomones, induced by Nezara viridula feeding and oviposition on bean spp., that attract the egg parasitoid Trissolcus basalis. J Chem Ecol 30:945-964

Copatti JF, Oliveira NC (2011) Danos iniciais causados pelos percevejos Dichelops melacanthus e Euschistus heros (Hemiptera: Pentatomidae) em plantas de milho. Campo Digit Campo Mourão 6:1-8

D’Alessandro M, Brunner V, Gv Mérey, Turlings TCJ (2009) Strong attraction of the parasitoid Cotesia marginiventris towards minor volatile compounds of maize. J Chem Ecol 35:999-1008. doi:10. 1007/s10886-009-9692-7

de Boer JG, Hordijk CA, Posthumus MA, Dicke M (2008) Prey and non-prey arthropods sharing a host plant: effects on induced volatile emission and predator attraction. $\mathrm{J}$ Chem Ecol 34:281-290

De Moraes CM, Lewis WJ, Paré PW, Alborn HT, Tumlinson JH (1998) Herbivore-infested plants selectively attract parasitoids. Nature 393:570-573

Development Core Team R (2007) R: a language and environment for statistical computing. R Foundation for Statistical Computing, Vienna

Dicke M, Baldwin IT (2010) The evolutionary context for herbivoreinduced plant volatiles: beyond the 'cry for help'. Trends Plant Sci 15:167-175. doi:10.1016/j.tplants.2009.12.002

Du Y-J, Poppy GM, Powell W (1996) Relative importance of semiochemicals from first and second trophic levels in host foraging behavior of Aphidius ervi. J Chem Ecol 22:1591-1605

Fatouros NE, Dicke M, Mumm R, Meiners T, Hilker M (2008) Foraging behavior of egg parasitoids exploiting chemical information. Behav Ecol 19:677-689. doi:10.1093/beheco/ arn011

Fritzsche Hoballah ME, Tamò C, Turlings TCJ (2002) Differential attractiveness of induced odors emitted by eight maize varieties for the parasitoid Cotesia marginiventris: is quality or quantity important? J Chem Ecol 28:951-968

Gouinguené S, Degen T, Turlings TCJ (2001) Variability in herbivore-induced odour emissions among maize cultivars and their wild ancestors. Chemoecology 11:9-16

Higuchi H (1992) Population prevalence of occurrence and spatial distribution pattern of Piezodorus hybneri adults (Heteroptera: Pentatomidae) on soybeans. Appl Entomol Zool 27:363-369

Hilker M, McNeil JN (2008) Chemical and behavioral ecology in insect parasitoids: how to behave optimally in a complex odorous environment. In: Wajnberg E, Bernstein C, Van Alphen JJM (eds) Behavioral ecology of insect parasitoids: from theoretical approaches to field applications. Blackwell, Malden, pp $97-100$

Hilker M, Meiners T (2010) How do plants "notice" attack by herbivorous arthropods? Biol Rev 85:267-280. doi:10.1111/j. 1469-185X.2009.00100.x

Hilker M, Kobs C, Varama M, Schrank K (2002) Insect egg deposition induces Pinus sylvestris to attract egg parasitoids. J Exp Biol 205:455-461

Karban R, Myers JH (1989) Induced plant-responses to herbivory. Annu Rev Ecol Syst 20:331-348

Kariyat RR, Mauck KE, De Moraes CM, Stephenson AG, Mescher MC (2012) Inbreeding alters volatile signalling phenotypes and influences tri-trophic interactions in horsenettle (Solanum carolinense L.). Ecol Lett 15:301-309. doi:10.1111/j.1461-0248. 2011.01738.x

Koornneef A, Pieterse CMJ (2008) Cross talk in defense signaling. Plant Physiol 146:839-844. doi:10.1104/pp.107.112029

Laumann RA, Aquino MFS, Moraes MCB, Pareja M, Borges M (2009) Response of the egg parasitoids trissolcus basalis and Telenomus podisi to compounds from defensive secretions of stink bugs. J Chem Ecol 35:8-19. doi:10.1007/s10886-0089578-0

Laumann RA, Cokl A, Lopes APS, Fereira JBC, Moraes MCB, Borges M (2011) Silent singers are not safe: selective response of a parasitoid to substrate-borne vibratory signals of stink bugs. Anim Behav 82:1175-1183. doi:10.1016/j.anbehav.2011.08.017

Lopes APS, Diniz IR, Moraes MCB, Borges M, Laumann RA (2012) Defesas induzidas por herbivoria e interações específicas no sistema tritrófico soja percevejos parasitoides de ovos. Pesquisa Agropecuária Brasileira 47:875-878 
Malaguido AB, Panizzi AR (1998) Damage of Euschistus heros (F.) (Hemiptera: Pentatomidae) to sunflower seeds. Anais da Sociedade Entomológica do Brasil 27:535-541

McCormick AC, Unsicker SB, Gershenzon J (2012) The specificity of herbivore-induced plant volatiles in attracting herbivore enemies. Trends Plant Sci 17:303-310. doi:10.1016/j.tplants.2012. 03.012

Melo Machado RC, Sant'Ana J, Blassioli-Moraes MC, Laumann RA, Borges M (2014) Herbivory-induced plant volatiles from Oryza sativa and their influence on chemotaxis behaviour of Tibraca limbativentris Stal. (Hemiptera: Pentatomidae) and egg parasitoids. Bull Entomol Res 104:347-356. doi:10.1017/ S0007485314000133

Michereff MFF, Laumann RA, Borges M, Michereff-Filho M, Diniz IR, Neto ALF, Moraes MCB (2011) Volatiles mediating a plantherbivore-natural enemy interaction in resistant and susceptible soybean cultivars. J Chem Ecol 37:273-285. doi:10.1007/ s10886-011-9917-4

Michereff MFF, Borges M, Laumann RA, Diniz IR, Neto ALF, Moraes MCB (2013) Influence of volatile compounds from herbivore-damaged soybean plants on searching behavior of the egg parasitoid Telenomus podisi. Entomol Exp Appl 147:9-17

Moraes MCB, Laumann R, Sujii ER, Pires C, Borges M (2005) Induced volatiles in soybean and pigeon pea plants artificially infested with the neotropical brown stink bug, Euschistus heros, and their effect on the egg parasitoid, Telenomus podisi. Entomol Exp Appl 115:227-237

Moraes MCB, Pareja M, Laumann RA, Hoffmann-Campo CB, Borges M (2008) Response of the parasitoid Telenomus podisi to induced volatiles from soybean damaged by stink bug herbivory and oviposition. J Plant Interact 3:111-118

Moraes MCB et al (2009) Attraction of the stink bug egg parasitoid Telenomus podisi to defence signals from soybean activated by treatment with cis-jasmone. Entomol Exp Appl 131:178-188. doi:10.1111/j.1570-7458.2009.00836.x

Mumm R, Hilker M (2005) The significance of background odour for an egg parasitoid to detect plants with host eggs. Chem Senses 30:337-343. doi:10.1093/chemse/bji028

Mumm R, Schrank K, Wegener R, Schulz S, Hilker M (2003) Chemical analysis of volatiles emitted by Pinus sylvestris after induction by insect oviposition. J Chem Ecol 29:1235-1252

NIST (2008) NIST/EPA/NIH Mass Spectral Library 2008

Ode PJ (2013) Plant defences and parasitoid chemical ecology. In: Wajnberg E, Colazza S (eds) Chemical ecology of insect parasitoids. Wiley, Oxford, pp 11-36

Panizzi AR (1997) Wild hosts of pentatomids: ecological significance and role in their pest status on crops. Annu Rev Entomol 42:99-122
Panizzi AR, Vivan LM (1997) Seasonal abundance of the neotropical brown stink bug, Euschistus heros, in overwintering sites, and the breaking of dormancy. Entomol Exp Appl 82:213-217

Pareja M, Mohib A, Birkett MA, Dufour S, Glinwood RT (2009) Multivariate statistics coupled to generalized linear models reveal complex use of chemical cues by a parasitoid. Anim Behav 77:901-909. doi:10.1016/j.anbehav.2008.12.016

Pashalidou FG, Huigens ME, Dicke M, Fatouros NE (2010) The use of oviposition-induced plant cues by Trichogramma egg parasitoids. Ecol Entomol 35:748-753. doi:10.1111/j.1365-2311. 2010.01235.x

Piñero JC, Dorn S (2007) Synergism between aromatic compounds and green leaf volatiles derived from the host plant underlies female attraction in the oriental fruit moth. Entomol Exp Appl 125:185-194

Rodriguez-Saona C, Kaplan I, Braasch J, Chinnasamy D, Williams L (2011) Field responses of predaceous arthropods to methyl salicylate: a meta-analysis and case study in cranberries. Biol Control 59:294-303. doi:10.1016/j.biocontrol.2011.06.017

Rodríguez-Saona C, Chalmers JA, Raj S, Thaler JS (2005) Induced plant responses to multiple damagers: differential effects on an herbivore and its parasitoid. Oecologia 143:566-577

Silva CC, Laumann RA, Blassioli MC, Pareja M, Borges M (2008) Euschistus heros mass rearing technique for the multiplication of Telenomus poldisi. Pesquisa Agropecuária Brasileira 43:575-580

Storeck A, Poppy GM, van Emden HF, Powell W (2000) The role of plant chemical cues in determining host preference in the generalist aphid Aphidius colemani. Entomol Exp Appl 97:41-46

Sujii ER, Costa MLM, Pires CSS, Colazza S, Borges M (2002) Inter and intra-guild interactions in egg parasitoid species of the soybean stink bug complex. Pesquisa Agropecuária Brasileira 37:1541-1549

Tillman PG, Northfield TD, Mizell RF, Riddle TC (2009) Spatiotemporal patterns and dispersal of stink bugs (Heteroptera: Pentatomidae) in peanut-cotton farmscapes. Environ Entomol 38:1038-1052

van Poecke RMP, Dicke M (2004) Indirect defence of plants against herbivores: using Arabidopsis thaliana as a model plant. Plant Biol 6:387-401

Vet LEM, Dicke M (1992) Ecology of infochemical use by natural enemies in a tritophic context. Annu Rev Entomol 37:141-172

Wäschke N, Meiners T, Rostás M (2013) Foraging strategies of parasitoids in complex chemical environments. In: Wajnberg E, Colazza S (eds) Chemical ecology of insect parasitoids. Wiley, Chichester, pp 37-63 